\title{
FAKTOR INTERNAL DAN EKSTERNAL PENGEMBANGAN AGRIBISNIS HORTIKULTURA PETANI MUDA (Studi Kasus Komunitas Katenzo, Kecamatan Pangalengan)
}

\author{
Sarah Ramadhina*, Lucyana Trimo \\ Program Studi Agribisnis, Universitas Padjadjaran \\ Jl. Raya Bandung Sumedang Jatinangor, Sumedang 45363 \\ *Corresponding author: sarahrdhina27@gmail.com
}

\begin{abstract}
The declining interest of the younger generation in agriculture is the main factor of decreasing farmers in Indonesia. The decline is due to several factors, including youth's assessment that the agricultural sector is unprofitable, less prestigious, and synonymous with poverty. It is necessary to know young farmers' strategies who are still surviving in the agribusiness sector. This strategy can be used as a reference for young farmers individually or in groups in carrying out agribusiness activities. The Katenzo community is a farmer group in the Pangalengan sub-district consisting of young farmers. The Katenzo community has 13 members engaged in the horticulture sub-sector agribusiness, 13 members will be the informant in this case. This study aims to identify various internal and external factors that affect horticultural agribusiness development in the Katenzo Community. The research was conducted using qualitative methods with case study techniques to find out various indepth data according to the object's conditions and uniqueness. The research data were obtained through observation, in-depth interviews, documentation, and literature study, then be analyzed using the IFAS, EFAS, IE, and SWOT matrix. Based on the results of the IFAS Matrix, the total score for the strengths and weaknesses of the Katenzo community is 2.564. The total score of the EFAS Matrix obtained from the threat and opportunity score is 2.534. The results of the IE Matrix show that the Katenzo Community is in cell V, namely Hold and Maintain.
\end{abstract}

Keywords: agribusiness, community, development, horticulture, young farmers

\begin{abstract}
Abstrak: Menurunnya minat generasi muda terhadap pertanian menjadi faktor utama berkurangnya jumlah petani di Indonesia. Hal tersebut disebabkan oleh beberapa faktor diantaranya, penilaian para pemuda yang menganggap sektor pertanian tidak menguntungkan, kurang bergengsi, dan identik dengan kemiskinan. Perlu diketahui strategi yang digunakan petani muda yang masih bertahan dalam bidang agribisnis. Strategi tersebut dapat menjadi acuan petani muda secara individu ataupun kelompok dalam menjalankan kegiatan agribisnis. Komunitas Katenzo merupakan suatu kelompok tani di Kecamatan Pangalengan yang dihimpun dari para petani muda. Komunitas Katenzo beranggotakan 13 orang yang bergerak dalam agribisnis subsektor hortikultura, 13 orang tersebut akan menjadi informan dalam penelitian ini. Penelitian ini bertujuan untuk mengidentifikasi berbagai faktor internal dan eksternal yang memengaruhi pengembangan agribisnis hortikultura di Komunitas Katenzo. Penelitian dilakukan menggunakan metode kualitatif dengan teknik studi kasus untuk mengetahui secara mendalam berbagai data sesuai dengan kondisi dan keunikan objek. Data penelitian diperoleh melalui observasi, wawancara mendalam, dokumentasi, dan studi literatur, yang selanjutnya akan dianalisis menggunakan matriks IFAS, EFAS, dan IE. Berdasarkan hasil Matriks IFAS, perolehan total skor kekuatan dan kelemahan komunitas Katenzo sebesar 2,564. Total skor Matriks EFAS yang diperoleh dari skor
\end{abstract}


ancaman dan peluang sebesar 2,534. Hasil dari Matriks IE, Komunitas Katenzo berada di sel V yakni Hold and Maintain (Menjaga dan Pertahanan).

Kata kunci: agribisnis, hortikultura, komunitas, pengembangan, petani muda

\section{PENDAHULUAN}

Generasi muda sangat dibutuhkan dalam membangun pertanian di Indonesia, sebab saat ini semakin sedikit orang yang tinggal di desa semakin sedikit orang yang bekerja di sektor pertanian (Arvianti et al., 2019). Pemerintah juga memberikan perhatian yang lebih besar kepada petani kecil dan generasi muda agar mau terjun langsung ke sektor pertanian.

Berdasarkan data Badan Pusat Statistik (BPS), pada 2017-2018 terjadi penurunan jumlah petani muda sebanyak 415.000 petani. Krisis regenerasi petani ini dikhawatirkan mengancam ketahanan pangan nasional.

Batasan umur petani muda menurut Kementerian Pertanian Republik Indonesia (2020), yaitu petani yang berusia $<39$ tahun Data hasil survey pertanian antar sensus tahun 2018 pada Tabel 1 menunjukkan bahwa jumlah petani usia $<39$ tahun di Jawa Barat masih sedikit dibandingkan dengan petani usia $>39$ tahun. Kabupaten Bandung sebagai salah satu sentra pertanian Jawa Barat juga masih tergolong kecil jumlah petani mudanya dibandingkan dengan kabupaten lain. Menurut Susilowati (2016), terdapat berbagai alasan yang menjadi penyebab menurunnya minat pemuda untuk bekerja di sektor pertanian, salah satunya adalah sektor pertanian memiliki citra yang kurang bergengsi dengan teknologi yang belum maju serta belum dapat memberikan pendapatan yang memadai.
Secara umum, petani-petani muda tidak mampu bertahan lama, bahkan secara keseluruhan hanya $16 \%$ yang mampu mempertahankan dan mengembangkan usahanya, sisanya mereka beralih ke sektor usaha lain sebagai mata pencaharian mereka. Setiawan (2006) yang menjelaskan banyaknya pemuda desa yang meninggalkan sektor pertanian disebabkan oleh penilaian para pemuda yang menganggap sektor pertanian tidak menguntungkan, kurang bergengsi, dan identik dengan kemiskinan.

Pangalengan merupakan salah satu kecamatan di Kabupaten Bandung, Provinsi Jawa Barat yang terdiri dari 13 desa dengan luas wilayah $195,41 \mathrm{~km}^{2}$ yang terdiri dari 5.897,65 hektar berupa tanah kering, 5.893,52 hektar berupa tanah perkebunan dan sisanya berupa tanah sawah dan tanah basah yang mengandalkan sektor pertanian sebagai penyumbang terbesar dalam pendapatan daerahnya.

Dari 13 desa yang ada di Kecamatan Pangalengan, 11 diantaranya memiliki sumber penghasilan utama yang berasal dari sektor pertanian. Desa-desa tersebut diantaranya Desa Margaluyu, Desa Sukaluyu, Desa Warnasari, Desa Pulosari, Desa Margamekar, Desa Sukamanah, Desa Margamukti, Desa Pangalengan, Desa Margamulya, Desa Tribaktimulya dan Desa Lamajang. Sementara Desa Wanasuka dan Banjarsari memiliki

Tabel 1. Jumlah petani menurut Kabupaten/Kota dan kelompok umur

\begin{tabular}{lccccccc}
\hline \multirow{2}{*}{ Kabupaten } & $<25$ & $25-34$ & $35-44$ & $45-54$ & $55-64$ & $\geq 65$ & Jumlah (orang) \\
\hline Bogor & 4.783 & 25.038 & 55.035 & 75.525 & 55.300 & 31.512 & 247.193 \\
Sukabumi & 7.880 & 40.476 & 85.561 & 106.487 & 79.845 & 49.822 & 370.071 \\
Cianjur & 7.792 & 45.474 & 82.164 & 98.292 & 76.949 & 48.812 & 359.483 \\
Bandung & 4.515 & 16.761 & 36.598 & 43.630 & 38.920 & 28.829 & 169.253 \\
Garut & 6.861 & 33.268 & 70.408 & 85.809 & 63.640 & 43.642 & 303.628 \\
\hline Jawa Barat & 67.634 & 358.902 & 816.979 & 1.094 .946 & 881.498 & 602.115 & 3.821 .603
\end{tabular}

Sumber: Hasil Survey Pertanian antar Sensus (SUTAS) 2018 (diolah) 
sumber penghasilan utama dari sektor jasa (Badan Pusat Statistik, 2018). Desa Margamukti merupakan desa dengan jumlah buruh tani tertinggi di Kecamatan Pangalengan. Di Desa Margamukti sudah mulai terbentuk kelompok petani muda atau komunitas yang bernama Katenzo.

Komunitas petani muda Katenzo merupakan salah satu produsen sayuran di Kecamatan Pangalengan, Kabupaten Bandung. Katenzo baru terbentuk selama 3 tahun dari tahun 2017, kelompok ini masih bertahan walaupun saat ini, pada awal tahun 2020 bisnis mereka dihadapi tantangan mewabahnya pandemi Covid-19. Dalam kegiatan pengembangan usahanya komunitas petani muda Katenzo menghadapi permasalahan dari internal maupun eksternal diantaranya dalam hal usaha, organisasi dan manajemen, hama dan penyakit, cuaca, sarana dan prasarana yang masih sederhana serta permodalan yang masih terbatas. Penilaian terhadap strategi usaha sayuran yang tengah dikembangkan oleh para petani muda perlu dilakukan sehingga dapat diketahui faktor-faktor internal dan eksternal guna mengevaluasi perkembangan usahanya tersebut dan dapat dikombinasikan untuk dihasilkan prioritas pengembangan usahatani petani muda hortikultura.

Sebagai pengusaha pemula, petani muda membutuhkan dukungan yang dapat membantu dalam menghadapi hambatan dalam memulai sebuah bisnis, yaitu sumberdaya, layanan dan juga jejaring bisnis (Mukti et al., 2018). Penentuan cara mendukung petani muda menjadi prioritas politik untuk masa depan kebijakan pertanian tentang dunia pertanian skala kecil (Hazell, 2005).

Petani harus memiliki kemampuan untuk memahami segala permasalahan dan peluang yang terdapat dalam bisnis pertanian. Kemauan untuk berempati terhadap lingkungan, memahami pertanian sebagai bisnis yang unik dan senantiasa menjadi seorang pembelajar telah menjadi keharusan bagi petani muda agar mereka dapat bertahan dan berkembang dalam bisnis pertanian (Lans et al., 2017). Sebagai petani harus mengetahui peluang dan ancaman yang akan dihadapi dalam pengembangan bisnis pertanian untuk terus tetap bertahan dalam membangun ekosistem pertanian berkelanjutan.
Penelitian ini bertujuan untuk mengetahui faktor Internal dan eksternal yang dibutuhkan kelompok petani muda Katenzo di Kecamatan Pangalengan dan menganalisis apa saja faktor pendorong dan faktor penghambat yang nantinya dapat digunakan sebagai masukan dalam perumusan strategi pengembangan agribisnis hortikultura komunitas Katenzo.

\section{METODE PENELITIAN}

Penelitian ini menggunakan pendekatan kualitatif yang dilakukan di Komunitas Katenzo yang berada di Kecamatan Pangalengan pada Bulan Oktober 2020. Penelitian dengan analisis kualitatif adalah penelitian yang bertujuan untuk mencari maksud dari suatu fenomena. McMillan dan Schumacher (1997), mendeskripsikan metode kualitatif sebagai tradisi tertentu dalam ilmu pengetahuan sosial yang secara fundamental bergantung pada pengamatan terhadap manusia dalam kawasannya sendiri dan berhubungan dengan orang-orang tersebut dalam bahasa dan istilahnya. Pendapat lain mengenai metode kualitatif dijelaskan oleh Mantra (2004) dan Moleong et al. (2004), bahwa metode kualitatif sebagai prosedur penelitian yang menghasilkan data deskriptif berupa kata-kata atau lisan dari orang-orang dan perilaku yang dapat diamati. Metode kualitatif berusaha mengungkap berbagai keunikan yang terdapat dalam individu, kelompok, masyarakat, atau organisasi dalam kehidupan sehari-hari secara menyeluruh, rinci, dalam, dan dapat dipertanggungjawabkan secara ilmiah (Sukidin, 2002).

Teknik penelitian menggunakan studi kasus sebagai kegiatan ilmiah terstruktur yang dilakukan secara mendalam dan mendetail terhadap fenomena tertentu, yaitu fenomena yang sedang berlangsung. Sumber data primer dalam penelitian ini adalah data yang akan dikumpulkan berdasarkan hasil pengamatan dan wawancara mendalam secara langsung terhadap anggota kelompok petani muda Katenzo di Kecamatan Pangalengan. Data primer pada penelitian ini digunakan untuk mengetahui strategi yang digunakan untuk mengembangkan agribisnis hortikultura. Data sekunder yang digunakan pada penelitian ini berupa informasi atau literatur yang diperoleh 
dari internet, buku, surat kabar, berita aktual, jurnal, Badan Pusat Statistika (BPS) dan lain sebagainya yang berkaitan dengan strategi pengembangan agribisnis petani muda hortikultura. Informan sebagai subjek pada penelitian ini adalah 13 anggota komunitas Katenzo yang memproduksi sayuran eksklusif diantaranya adalah tanaman baby buncis, kol merah, bayam jepang, buah bit.

Data penelitian dianalisis dengan menggunakan SWOT dengan bantuan matriks IFAS dan EFAS untuk mengidentifikasi berbagai faktor strategis internal dan eksternal yang nantinya memengaruhi pengembangan agribisnis hortikultura yang dilakukan oleh komunitas petani muda Katenzo. (Rangkuti, 2016) menjelaskan bahwa analisis SWOT adalah proses identifikasi berbagai faktor secara sistematis untuk merumuskan strategi perusahaan atau organisasi. Analisis SWOT didasarkan pada logika yang dapat memaksimalkan kakuatan (Strenght) dan peluang (Oportunities), dan dapat meminimalkan kelemahan (Weaknesses) dan ancaman (Threats).

\section{HASIL DAN PEMBAHASAN}

\section{Gambaran Umum}

Komunitas Katenzo merupakan kelompok petani muda yang bergerak di subsistem hortikultura yang berada di Kecamatan Pangalengan. Komunitas Katenzo menghimpun para petani muda sebagai anggotanya. Kata Katenzo berasal dari bahasa sunda "Katenjo" yang memiliki arti "terlihat", arti dari katenjo ini diharapkan menjadi do'a suatu saat nanti Komunitas Katenzo mampu dipandang oleh banyak pihak dan bisa meningkatkan serta mengembangkan kesejahteraan para anggotanya.

Katenzo bergerak dalam bidang hortikulura dengan produk sayuran eksklusif yang belum banyak diusahakan petani hortikultura lain. Sayuran eksklusif di Indonesia masih memiliki harga pasaran yang cukup stabil dibandingkan jenis sayuran lokal lainnya karena saluran pemasaran sayuran eksklusif ini seperti restaurant atau supplier tetap. Permintaan pasar yang tinggi dan belum mampu terpenuhi juga menjadi alasan para petani anggota Komunitas Katenzo saling bekerjasama untuk memenuhi permintaan pasar. Jenis sayuran eksklusif yang banyak dibudidayakan oleh anggota Komunitas Katenzo diantaranya: poleng/bayam Jepang, kol merah, baby buncis/buncis kenya, buah bit dan lain-lain. Komunitas Katenzo juga tetap mengusahakan sayuran lokal, sayuran lokal yang banyak dibudidayakan diantaranya: cabai, tomat, kubis, sawi, dan lain-lain.

Komunitas Katenzo diresmikan oleh Kepala Desa Margamukti melalui Surat Keputusan Nomor 145.4/SK.06/III/2017 dan domisili Komunitas Katenzo sudah diresmikan oleh Kepala Desa Margamukti melalui Surat Keputusan Nomor 29.4/SK.06/DS/II/2018 dengan alamat di RT 04/RW 06, Desa Margamukti, Kecamatan Pangalengan.

Tujuan atau arah utama Komunitas Katenzo dihimpun dalam sebuah Visi dan Misi. Adapun visi dan Misi komunitas Katenzo. Visi Komunitas Katenzo: a) pemberdayaan Perekonomian, b) mewujudkan kebersamaan dan kegotongroyongan, c) meningkatkan hasil produksi pertanian khususnya tanaman hortikultura. Misi dalam terwujudnya visi Komunitas Katenzo: a) tercapainya kesejahteraan para petani dengan meningkatkan hasil produksi pertanian khususnya petani buncis, (b) mengembangkan kebersamaan dan kekompakan.

Komunitas Katenzo membentuk sebuah gerakan dengan mengadakan kegiatan-kegiatan yang bermanfaat bagi para anggotanya. Kegiatan tersebut dilakukan berkaitan dengan kegiatan produksi atas dasar kebersamaan. Para anggota Komunitas Katenzo bergotong royong dalam mencapai tujuan bersama. Adapun gerakan atau kegiatan yang dimiliki diantaranya: Gerakan dengan kegiatan gotong royong: a) Gerakan kekompakan dalam kegotong-royongan, Keserempakan dalam pola tanam, b) Gerakan pemberantasan hama dalam memotong siklus hidup OPT melalui pengolahan tanah yang baik. Gerakan keamanan dan ketertiban: a) Gerakan siskamling, b) Gerakan ketertiban dengan penjadwalan pengolahan tanah, pengairan dan pengobatan. Upaya peningkatan produksi: a) mengadakan sekolah lapangan pertanian, b) pemakaian bibit unggul, c) pengolahan tanah yang baik dan sempurna, d) keseragaman/ keserempakan dalam waktu saat penanaman, e) budidaya tanaman sehat. 
Analisis Faktor Internal dan Eksternal Pengembangan Agribisnis Hortikultura Komunitas Katenzo

Faktor Internal

Dalam analisis lingkungan internal Komunitas Katenzo akan diketahui kekuatan-kelemahan dari komunitas petani muda muda Katenzo pada sumberdaya, pemasaran, produktifitas, pemasaran, dan keuangan yang dianalisis berdasarkan faktor yang memengaruhi dari dalam dan dari luar komunitas.

Berdasarkan Tabel 2, terdapat 15 faktor internal yang terdiri atas 9 kekuatan dan 6 kelemahan. Faktor yang dianggap paling menunjang pengembangan agribisnis hortikultura Komunitas Katenzo adalah memproduksi sayuran eksklusif seperti baby buncis, kol/kubis merah, bayam jepang/poleng, buah bit, dan lain-lain (skor: 0,320). Komunitas Katenzo yang berada di daerah Kecamatan Pangalengan sebagai daerah dataran tinggi memproduksi baby buncis sebagai komoditas utama. Memproduksi baby buncis menjadi kelebihan dari Komunitas Katenzo karena masih sedikit yang memproduksi komoditas tersebut di Pangalengan, mayoritas di daerah Pangalengan memproduksi kentang, tomat atau sayuran lokal lainnya. Faktor Internal yang menghambat pengembangan agribisnis hortikultura komunitas Katenzo adalah terbatasnya modal anggota (skor: 0,080), terbatasnya modal anggota menjadi faktor utama penghambat pengembangan karena berawal dari kurangnya modal anggota petani mengurangi jumlah produksi, mengurangi jumlah tenaga kerja, tidak dapat menambah luas lahan dan perkembangan usaha lainnya.

\section{Faktor Eksternal}

Dalam faktor eksternal terdapat peluang dan ancaman dari luar komunitas Katenzo yang memengaruhi pengembangan komunitas. Peluang merupakan kondisi eksternal yang menunjang lembaga dalam mencapai tujuan tertentu. Ancaman merupakan faktor dari luar komunitas Katenzo yang menghambat tercapainya suatu tujuan.

Berdasarkan Tabel 3, dapat diketahui bahwa terdapat 12 faktor eksternal terdiri atas 6 peluang dan 6 ancaman yang dianggap mampu memengaruhi pengembangan agribisnis hortikultura komunitas Katenzo. Peluang kerjasama dengan supplier ekspor menjadi

Tabel 2. Matrik IFAS

\begin{tabular}{|c|c|c|c|c|}
\hline & Faktor-Faktor Strategi Internal & Bobot & Rating & Skor \\
\hline & \multicolumn{4}{|l|}{ Kekuatan: } \\
\hline a. & Letak yang strategis berdekatan dengan pasar induk & 0,053 & 3 & 0,160 \\
\hline b. & $\begin{array}{l}\text { Kondisi fisik lingkungan yang sesuai dengan syarat tumbuh tanaman } \\
\text { hortikultura }\end{array}$ & 0,067 & 3,5 & 0,233 \\
\hline c. & Mempunyai visi dan misi untuk pengembangan agribisnis hortikultura & 0,067 & 3 & 0,200 \\
\hline d. & SDM petani muda di Komunitas Katenzo produktif & 0,067 & 3 & 0,200 \\
\hline e. & Relasi komunitas Katenzo yang luas & 0,080 & 3,5 & 0,280 \\
\hline f. & $\begin{array}{l}\text { Katenzo memproduksi sayuran ekskulsif (baby buncis, bayam } \\
\text { jepang/poleng, kol/kubis merah dll) }\end{array}$ & 0,080 & 4 & 0,320 \\
\hline g. & Katenzo mempunyai media sosial & 0,053 & 2 & 0,107 \\
\hline h. & Katenzo mempunyai informasi pasar dan channel pasar & 0,080 & 3,8 & 0,304 \\
\hline \multirow[t]{3}{*}{ i. } & $\begin{array}{l}\text { Informasi budidaya, mayoritas keluarga anggota petani muda adalah } \\
\text { petani }\end{array}$ & 0,040 & 3 & 0,120 \\
\hline & Total Skor & & & 1,924 \\
\hline & Kelemahan: & & & \\
\hline a. & Struktur dan pembagian tugas anggota belum berjalan dengan baik & 0,080 & 1,5 & 0,120 \\
\hline b. & Belum mempunyai pencatatan keuangan komunitas yang baik & 0,053 & 2 & 0,107 \\
\hline c. & Kurangnya komitmen sebagian anggota dalam pemasaran hasil produksi & 0,067 & 1,6 & 0,107 \\
\hline d. & Kurangnya sarana teknologi & 0,080 & 1,5 & 0,120 \\
\hline e. & Terbatasnya modal anggota & 0,080 & 1 & 0,080 \\
\hline \multirow[t]{3}{*}{ f. } & Terbatasnya lahan dan tenaga kerja & 0,056 & 2 & 0,107 \\
\hline & Total Skor & & & 0,640 \\
\hline & TOTAL & 1,000 & & 2,564 \\
\hline
\end{tabular}

Sumber : Data Primer Diolah, 2021 
Ramadhina, S., Trimo, L.: Faktor Internal Dan Eksternal Pengembangan Agribisnis ...

Tabel 3. Matrik EFAS

\begin{tabular}{|c|c|c|c|c|}
\hline & Faktor-Faktor Strategi Eksternal & Bobot & Rating & Skor \\
\hline & Peluang: & & & \\
\hline a. & Kebutuhan hortikultura meningkat & 0,086 & 3,0 & 0,259 \\
\hline b. & Permintaan pasar akan sayuran eksklusif dan bibit baby buncis & 0,069 & 2,5 & 0,172 \\
\hline c. & Peluang budidaya sayuran eksklusif di Pangalengan & 0,103 & 3,5 & 0,362 \\
\hline d. & Peluang kerjasama dengan supplier ekspor & 0,103 & 4,0 & 0,414 \\
\hline e. & $\begin{array}{l}\text { Keterlibatan Dinas Pertanian daerah dalam fasilitasi saprotan kelompok } \\
\text { tani }\end{array}$ & 0,069 & 2,5 & 0,172 \\
\hline f. & $\begin{array}{l}\text { Teknologi dibidang pertanian yang semakin modern } \\
\text { Total Skor } \\
\text { Ancaman: }\end{array}$ & 0,069 & 3,0 & $\begin{array}{l}0,207 \\
1,586\end{array}$ \\
\hline a. & Pandemi Covid-19 & 0,086 & 1,5 & 0,129 \\
\hline & Hama dan penyakit tanaman & 0,069 & 2,5 & 0,172 \\
\hline c. & Harga Sayuran yang sangat berfluktuasi & 0,103 & 2,0 & 0,207 \\
\hline d. & Cuaca dan iklim saat ini tidak menentu & 0,069 & 2,0 & 0,138 \\
\hline e. & Subsidi dari pemerintah berkurang dan harga saprotan mahal & 0,086 & 1,5 & 0,129 \\
\hline f. & $\begin{array}{l}\text { Persaingan pasar sayuran eksklusif dengan daerah lain } \\
\text { Total Skor }\end{array}$ & 0,086 & 2,0 & $\begin{array}{l}0,172 \\
0,948\end{array}$ \\
\hline & TOTAL & 1,000 & & 2,534 \\
\hline
\end{tabular}

Sumber : Data Primer Diolah, 2021

peluang utama dalam pengembangan agribisnis komunitas Katenzo (skor: 0,414). Kerjasama dengan supplier saat ini menjadi andalan dari Komunitas Katenzo, karena kelompok tani atau komunitas Katenzo terbentuk untuk memenuhi permintaan pasar secara bersama. Keuntungan dari kerjasama yaitu permintaannya akan tetap, karena sudah pasti. Saat awal pandemi Covid19 , permintaan dari baby buncis tetap walaupun harga turun, karena sudah ada komitmen dari supplier Pontianak dan Singapura.

Faktor ancaman yang paling berpengaruh dalam pengembangan agribisnis pada komunitas Katenzo adalah pandemi Covid-19 dan subsidi dari pemerintah berkurang dan harga saprotan mahal (skor: 0,129), pandemi berpengaruh pda turunnya pendapatan dan permintaan terhadap komoditas yang dibudidayakan anggota komunitas Katenzo. Berkurangnya subsidi dari pemerintah dan mahalnya sarana produksi pertanian juga menjadi faktor ancaman dengan skor yang sama dengan ancaman pandemi Covid-19, karena modal yang dikeluarkan untuk melakukan budidaya hortikultura menjadi mahal, namun pendapatan menurun.

Berdasarkan matriks IFAS dan EFAS, kekuatan dan peluang merupakan faktor pendukung, serta kelemahan dan ancaman dapat menjadi faktor penghambat dalam pengembangan agribisnis hortikultura komunitas Katenzo. Hasil perolehan dan analisis data menunjukkan bahwa faktor pendorong yang paling berpengaruh dalam menjalankan pengembangan agribisnis komunitas Katenzo adalah produksi sayuran eksklusif di Pangalengan. Komoditas yang paling banyak diusahakan anggota komunitas Katenzo, antara lain baby buncis, bayam jepang, kol merah, selada kriting, buah bit, pagoda dan daun ketumbar. Di Pangalengan belum banyak yang membudidayakan sayuran eksklusif, komoditas terbanyak di Pangalengan masih sayuran lokal seperti kentang dan tomat.

Katenzo mempunyai informasi pasar dan channel pasar. Informasi pasar berperan penting dalam pengalokasian sumberdaya hasil produksi, penentuan harga jual, penentuan strategi bisnis untuk dapat mempertimbangkan penanggungan risiko penjualan hasil panen komoditas hortikultura. Komunitas Katenzo cukup mempunyai banyak informasi pasar, ketua komunitas Katenzo sering mencari informasi pasar dari dinas, internet, langsung ke pasar, dan mempunyai channel atau supplier link yang akan mengeksporkan hasil produksi baby buncis.

Relasi komunitas Katenzo yang luas. Komunitas Katenzo baru terbentuk selama tiga tahun dari tahun 2017 namun sudah ada 13 anggota dan 2 pembina yang terbentuk dalam struktur. Kemampuan ketua komunitas Katenzo 
dalam menghimpun para petani muda, mencari informasi ke dinas pertanian dan mencari informasi seputar budidaya baby buncis dan pemasaran baby buncis menghasilkan relasi yang luas.

Potensi Alam dan kondisi fisik lingkungan yang sesuai dengan syarat tumbuh tanaman hortikultura. Kecamatan Pangalengan yang berada di dataran tinggi atau pegunungan membuat suhu udara di kecamatan ini cukup sejuk, yaitu berkisar antara $16^{\circ} \mathrm{C}-25^{\circ} \mathrm{C}$ dan pada tahun 2015 curah hujan $1.996 \mathrm{~mm} /$ tahun dengan rata- rata $5,47 \mathrm{~mm} /$ perhari, keadaan iklim tersebut sangat cocok untuk ditanami komoditas hortikultura khususnya sayuran eksklusif baby buncis, kol merah, dan bayam jepang sebagai komoditas utama yang dipasarkan oleh komunitas Katenzo.

Peluang kerjasama dengan supplier ekspor. Kerjasama dengan supplier saat ini menjadi andalan dari komunitas Katenzo, karena kelompok tani atau komunitas Katenzo terbentuk untuk memenuhi permintaan pasar secara bersama. Keuntungan dari kerjasama yaitu permintaannya akan tetap, karena sudah pasti. Saat awal pandemi Covid-19, permintaan dari baby buncis tetap walaupun harga turun, karena sudah ada komitmen dari supplier Pontianak dan Singapura.

Faktor penghambat paling berpengaruh yang dihadapi komunitas Katenzo dalam pengembangan agribisnis hortikultura adalah sebagai berikut:

Subsidi dari pemerintah berkurang dan harga saprotan mahal. Bantuan dari pemerintah daerah hanya berupa fasilitas pertanian seperti cultivator, container, krey plastik. Pupuk dan pestisida menggunakan uang masing-masing anggota petani. Saat ini anggota komunitas Katenzo merasa bahwa subsidi dari pemerintah sudah sangat berkurang karena meningkatnya harga-harga obat, pupuk, vitamin untuk tanaman.

Pandemi Covid-19 menjadi salah satu faktor penghambat pengembangan agribisnis petani muda. Pembatasan Sosial karena Covid19 berpengaruh terhadap transportasi pengiriman barang, namun tidak terlalu menjadi kendala bagi anggota komunitas Katenzo karena sudah ada bandar atau pengepul langganan, dan kelompok tani Katenzo juga mempunyai anggota yang mengurus bidang pemasaran menjadi perantara atau pengumpul hasil panen anggota Katenzo lalu langsung menjualnya ke pasar. Anggota Katenzo yang tidak memproduksi baby buncis mengalami kerugian dipenjualan tanaman lain seperti sawi, cabai kol, brokoli, tomat, kentang karena mengalami penurunan permintaan dan penurunan harga yang sangat signifikan.

Terbatasnya modal anggota, keterbatasan modal menjadi kendala dalam memberikan upah kepada tenaga kerja. Kekurangan modal juga berdampak pada kecilnya luas lahan yang petani muda garap. Permodalan sangat berpengaruh pada usahatani karena saat ini harga saprotan (sarana produksi pertanian) mahal. Bagi para anggota petani muda Katenzo jika modal tidak sulit maka penjualan sayuran eksklusif akan sangat menguntungkan, termasuk jika mempunyai akomodasi trasnportasi kelompok yang dapat langsung dijual ke pasar atau supplier.

Belum mempunyai pencatatan keuangan komunitas yang baik. Menurut Rodjak (2006) kegunaan dari menganalisis neraca untung rugi pada kegiatan usahatani akan diketahui posisi keuangan suatu usahatani pada akhir tahun. Komunitas Katenzo belum mempunyai pencatatan atau pembukuan yang baik sehingga posisi keuangan setiap tahun atau setiap penjualan komoditas tidak diketahui secara pasti.

Terbatasnya lahan dan tenaga kerja, lahan garapan anggota komunitas Katenzo sangat bervariasi dari mulai lahan sewa hanya 70 tumbak hingga mempunyai lahan garapan seluas 3 ha. Lahan pertanian merupakan penentu dari pengaruh faktor produksi komoditas tanaman hortikultura, karena secara umum lahan garap yang luas dapat cenderung berpengaruh kepada peningkatan jumlah produksi yang dihasilkan. Anggota petani muda membutuhkan lahan dan tenaga kerja untuk meningkatkan hasil produksi hortikultura. Saat ini tenaga kerja sulit dicari karena banyak yang berubah profesi lebih memilih menjadi buruh di perusahaan dibandingkan menggarap lahan.

Kurangnya sarana teknologi, teknologi yang digunakan oleh para petani muda Katenzo masih menggunakan teknologi sederhana, teknologi modern yang terdapat pada komunitas ini adalah satu kultivator dari pemerintah daerah. Anggota petani muda ini ingin menggunakan teknologi modern namun terhalang oleh keterbatasan modal. Komunitas 
yang berusia muda ini cukup mudah dalam mengadopsi teknologi baru dan dapat lebih produktif dalam menghasilkan hasil produksi, namun keterbatasan keuangan menjadi kendala dalam mengembangkan produksi menggunakan teknologi modern.

\section{Matriks IE (Internal-Eksternal)}

Berdasarkan hasil evaluasi faktor strategis internal dan eksternal menggunakan Matriks IFAS dan EFAS, diketahui bahwa skor total faktor strategis internal komunitas Katenzo sebesar 2,564 dan skor total faktor strategis eksternal komunitas Katenzo sebesar 2,534. Hasil skor total faktor strategis tersebut gabungkan dengan penempatan total skor faktor strategis internal dari matriks InternalEksternal pada sumbu $\mathrm{X}$ dan total skor faktor strategis eksternal pada sumbu Y. Berdasarkan penggabungan seperti yang ada pada gambar 5 . tersebut diketahui bahwa posisi komunitas Katenzo berada pada sel V.

Tabel 4. Hasil Matriks Internal-Eksternal pada Komunitas Katenzo

\begin{tabular}{|c|c|c|c|c|}
\hline \multicolumn{5}{|c|}{ Total Skor EFAS 2,534 } \\
\hline$\tilde{\delta}_{0}$ & & $\begin{array}{l}\text { Tinggi: } \\
3,0-4,0\end{array}$ & $\begin{array}{l}\text { Sedang: } \\
2,0-2,99\end{array}$ & $\begin{array}{l}\text { Rendah: } \\
1,0-1,99\end{array}$ \\
\hline$\sum^{n}$ & $\begin{array}{l}\text { Tinggi: } \\
3,0-4,0\end{array}$ & I & II & III \\
\hline t) & $\begin{array}{l}\text { Sedang: } \\
2,0-2,99\end{array}$ & IV & V & VI \\
\hline 吾 & $\begin{array}{l}\text { Rendah: } \\
1,0-1,99\end{array}$ & VII & VIII & IX \\
\hline
\end{tabular}

Sumber : Data Primer Diolah, 2021

Berdasarkan hasil pemetaan pada Tabel 4, posisi perusahaan ada pada sel V yakni Hold and Maintain (Menjaga dan Pertahankan). Strategi umum yang dipakai adalah penetrasi pasar, pengembangan produk pada pengembangan pasar. Menurut Rusdiansyah (2016), divisi-divisi yang masuk dalam sel III, $\mathrm{V}$, atau VII dapat ditangani dengan baik melalui strategi menjaga dan mempertahankan (hold and maintain); penetrasi pasar dan pengembangan produk adalah dua strategi yang paling banyak digunakan dalam jenis divisi ini.

Menurut Robbin dan Coulter (1999), Strategi penetrasi pasar merupakan proses manajerial dibidang pemasaran untuk mengembangkan dan menjaga agar tujuan, skill, pengetahuan, sumberdaya, sesuai dengan peluang dan ancaman pada pasar yang selalu berubah-ubah dan bertujuan untuk menyempurnakan usaha dan produk perusahaan sehingga memenuhi target laba dan pertumbuhan. Pernyataan tersebut didukung oleh (Mutmainnah, 2016) yang menjelaskan penetrasi pasar berpengaruh positif terhadap kinerja pemasaran yang dihasilkan.

Penetrasi pasar dapat dilakukan dengan menggunakan kekuatan komunitas untuk mencapai peluang yang dimiliki dengan mempertahankan kualitas bibit baby dan hasil produksi baby buncis yang dihasilkan dengan melakukan peningkatan kegiatan promosi secara online untuk menjangkau konsumen atau supplier yang berkomitmen untuk bekerjasama.

Pengertian pengembangan produk dijelaskan oleh Swastha (2010), yang menjelaskan srategi pengembangan produk yaitu, memperbaiki bentuk-bentuk yang sudah ada, memperluas lini produk, menambah model produk, meniru strategi pesaing, dan menambah produk yang tidak ada kaitannya dengan lini yang ada. Pernyataan ini didukung oleh hasil penelitian Rini (2013) yang menjelaskan bahwa pengembangan produk mempunyai peran yang sangat besar dalam meningkatkan volume penjualan, suatu perusahaan harus selalu memantau atau mengikuti perkembangan selera konsumen ataupun keluhan-keluhan dari pelanggan. Suatu perusahaan atau usaha harus mengawasi taktit dan strategi pesaing agar dapat mengantisipasi lebih awal tindakan yang berkaitan dengan produk yang dihasilkan. Dalam pengembangan produk agribisnis komunitas Katenzo, strategi yang dapat dilakukan adalah dengan memaksimalkan produksi bibit dan hasil produksi baby buncis pada komunitas Katenzo guna mengoptimalkan permintaan pasar baby buncis. Strategi ini didukung melalui peningkatan kualitas bibit dan perbaikan packaging agar terlihat rapi.

Memanfaatkan lahan yang ada dengan sangat produktif, melakukan tumpang sari, memaksimalkan produksi bibit baby buncis, fokus kepada budidaya baby buncis merupakan strategi yang dapat dilakukan untuk memaksimalkan produktivitas hasil produksi. Selain itu, untuk strategi integrasi selanjutnya, komunitas perlu mempertahankan dan meningkatkan kepercayaan kepada konsumen atau supplier sebagai jaminan terhadap 
hubungan kerjasama sebagai produsen baby buncis atau komoditas hortikultura lainnya. Hal tersebut ditunjang oleh kekuatan komunitas yang memiliki relasi yang luas dengan mempunyai supplier tetap (Singapura dan Pontianak) dan punya banyak informasi pasar.

Komunitas Katenzo dapat melakukan strategi integrasi yakni dengan melakukan perbaikan pembukuan dan atau keuangan agar dapat mengetahui aliran dana yang keluar dan masuk pada komunitas dengan baik, mengatur alokasi dana untuk biaya operasional, subsidi anggota dan keperluan biaya tidak terduga komunitas Katenzo. Strategi integrasi lainnya yaitu promosi di media sosial seperti instagram, komunitas Katenzo sudah punya media sosial tersebut namun belum aktif promosi.

Strategi horizontal yang dapat diterapkan komunitas Katenzo yaitu dengan menjalin kemitraan dengan petani muda di sekitar. Melalui kemitraan tersebut dapat mengatasi permasalahan kurang terpenuhinya permintaan supplier baby buncis dan dapat menciptakan permintaan yang lebih tinggi terhadap bibit baby buncis dan hasil produksi baby buncis. Sehingga dapat memberikan keuntungan yang lebih optimal bagi komunitas Katenzo dan mitra komunitas Katenzo.

\section{KESIMPULAN}

Komunitas petani muda Katenzo yang terletak di Pangalengan memproduksi sayuran eksklusif, hal tersebut merupakan faktor internal yang menjadi kekuatan utama komunitas Katenzo. Faktor Internal yang menjadi kelemahan utama pada komunitas Katenzo yaitu terbatasnya modal anggota. Terbatasnya modal menjadi penghambat pengembangan faktor-faktor yang lainnya.

Faktor Eksternal yang menjadi peluang utama adalah peluang kerjasama dengan supplier ekspor. Sedangkan faktor eksternal yang menjadi ancaman berpengaruh bagi komunitas Katenzo adalah pandemi Covid-19 dan subsidi pemerintah berkurang sehingga harga sarana produksi pertanian mahal.

Strategi yang dapat dilakukan komunitas Katenzo yaitu menyusun SOP kelompok (Standart Operating Procedure) sehingga segala kegiatan yang dijalankan lebih terarah dan mampu menghindari kesalahan-kesalahan prosedural. Mengoptimalkan penggunaan media sosial untuk dijadikan tempat sharing dan alat promosi yang menarik. Mempertahankan kepercayaan dan meningkatkan kualitas pelayanan kepada supplier agar terus melakukan pembelian kepada komunitas Katenzo. Meningkatkan kepercayaan pemerintah daerah kepada komunitas Katenzo sehingga kegiatan yang dilakukan oleh komunitas Katenzo selalu didukung. Menambah anggota Katenzo agar dapat memaksimalkan hasil produksi untuk memenuhi permintaan pasar dan mengantisipasi kurangnya hasil produksi karena hama dan penyakit atau gagal panen karena cuaca. Hasil analisis strategi yang diperoleh akan dilakukan oleh komunitas Katenzo sebagai referensi pengembangan bisnis pertanian komunitas.

\section{DAFTAR PUSTAKA}

Arvianti, E. Y., Masyhuri, M., Waluyati, L. R., \& Darwanto, D. H. (2019). Gambaran krisis petani muda Indonesia. Agriekonomika, 8(2), 168-180.

Badan Pusat Statistika. (2018). Produksi Hortikultura Sayuran dan Buah Semusim Provinsi Jawa Barat 2018. Bandung: BPS Jawa Barat.

Harini, C., \& Yulianeu, Y. (2018). Strategi penetrasi pasar UMKM Kota Semarang menghadapi era pasar global MEA. Jurnal Ekonomi Dan Bisnis, 21(2), 361-381.

Hazell, P. B. R. (2005). Is there a future for small farms? Agricultural Economics, 32(1), 93-101. https://doi.org/ 10.1111/j.0169-5150.2004.00016.x.

Kementerian Pertanian Republik Indonesia (2020). Statistik Pertanian Agricultural Statistics 2020. Jakarta: Pusat Data dan Sistem Informasi Pertanian, Kementerian Pertanian Republik Indonesia.

Lans, T., Seuneke, P., \& Klerkx, L. (2017). Encyclopedia of Creativity, Invention, Innovation and Entrepreneurship. New York: Springer.

Mantra, I. B. (2004). Filsafat Penelitian \& Metode Penelitian Sosial. Yogyakarta: Pustaka Pelajar. 
Ramadhina, S., Trimo, L.: Faktor Internal Dan Eksternal Pengembangan Agribisnis ...

McMillan, J.H \& Schumacher, S. (1997). Research in Education, a Conceptual Introduction. New York: Longman.

Moleong, Lexi J, \& Edisi, P. (2004). Metodologi Penelitian. Bandung: Penerbit Remaja Rosdakarya.

Mukti, G. W., Rasmikayati, E., Kusumo, R. A. B., \& Fatimah, S. (2018). Perilaku kewirausahaan petani mangga dalam sistem agribisnis di Kabupaten Majalengka Provinsi Jawa Barat. Mimbar Agribisnis, 4, 40-56.

Mutmainnah, A. C. (2016). Studi tentang pengaruh kemampuan merespon pasar dan inovasi produk terhadap penetrasi pasar pada kinerja pemasaran (Studi empiris pada: Industri rumahan telur asin di Kabupaten Brebes) [Thesis]. Universitas Diponegoro, Semarang.

Rangkuti, F. (2016). Teknik Membedah Kasus Bisnis Analisis SWOT. Jakarta: Gramedia Pustaka Utama.

Rini, E. S. (2013). Peran pengembangan produk dalam meningkatkan penjualan. Jurnal Ekonom, 16(1), 30-38.
Robbins, S. P. \& Coulter, M. 1999. Manajemen. Edisi ke-enam. Jakarta: PT. Prenhallindo.

Rodjak, A. 2006. Manajemen Usaha Tani. Jilid II. Bandung: Pustaka Gratuna.

Rusdiansyah, R. (2016). Analisis strategi aplikasi penagihan dengan Metode SWOT. Bina Insani ICT Journal, 3(1), 145-153.

Swastha, B. (2010). Manajemen Pemasaran: Analisa dan Perilaku Konsumen. Yogyakarta: BPFE UGM.

Setiawan, I. (2006). Peran sektor pertanian dalam penyerapan tenaga kerja di Indonesia. Jurnal Geografi Gea, 6(1), 1-6.

Sukidin. (2002). Manajemen Penelitian Tindakan Kelas. Surabaya: Insan Cendekia.

Susilowati, S. H. (2016). Fenomena penuaan petani dan berkurangnya tenaga kerja muda serta implikasinya bagi kebijakan pembangunan pertanian. Forum penelitian Agro Ekonomi, 34(1), 35-55. 